\title{
Corticosteroids in infant chronic lung disease
}

\author{
C. May, A. Greenough
}

ABSTRACT: Corticosteroids in infant chronic lung disease. C. May, A. Greenough.

Chronic lung disease (CLD), defined as chronic oxygen dependency at 36 weeks postmenstrual age, is increasing and associated with chronic respiratory morbidity and high health care utilisation at follow up. Many strategies, tested in randomised trials, have failed to reduce CLD. In contrast, corticosteroids if given systemically within the first two weeks after birth reduce CLD and may also favourably influence survival. Unfortunately, systemically administered corticosteroids have many acute side-effects and adversely affect long term neurodevelopmental outcome. If given by inhalation, corticosteroids have fewer adverse effects, but are less efficacious. Further research is required to accurately identify infants at highest risk of developing CLD, the corticosteroid dosage associated with a positive risk: benefit ratio and preferably a safer and more effective alternative therapy. Monaldi Arch Chest Dis 2004; 61: 3, 162-166.

Keywords: Chronic lung disease, corticosteroids.

Division of Asthma, Allergy and Lung Biology; Guy's, King's and St Thomas' School of Medicine, King's College London.

Correspondence: Professor Anne Greenough; Dept of Child Health; King's College Hospital; London SE5 9PJ UK; e-mail: anne.greenough@kcl.ac.uk

\section{Introduction}

Chronic lung disease (CLD), usually defined as oxygen dependency beyond 36 weeks postmenstrual age (PMA), is a frequent consequence of very premature birth. It affects between 43 and $47 \%$ of infants born at 23 to 25 weeks of gestation and between 38 and $40 \%$ of infants born at 26 to 28 weeks of gestation [1]. CLD places a significant burden on health care provision; re-hospitalisation of affected children is common in the first two years [2]. It is, therefore, desirable to identify strategies which will prevent or treat CLD; unfortunately, many of those tested have been ineffective. Randomised trials have failed to demonstrate that use of different ventilation strategies, including patient triggered ventilation (PTV) [3] high frequency positive pressure ventilation (HFPPV) [3] and high frequency oscillatory ventilation (HFOV) [1] prevent the development of CLD [4]. Similarly, treatment with antenatal glucocorticoids [5], postnatal surfactant [6] or fluid restriction [7] are unsuccessful.

CLD is an inflammatory condition [8,9], thus an alternative approach has been to examine the impact of therapies with anti-inflammatory properties. Corticosteroids reduce inflammatory mediators and neutrophil influx in the airways [10]. In addition, they decrease bronchospasm, leukotriene release, microvascular permeability and pulmonary oedema [11], but enhance surfactant synthesis [12]. As a consequence, the role of corticosteroids in the prevention and treatment of CLD has been assessed in many studies. The aim of this review is to highlight the benefits and side-effects of corticosteroid treatment and determine whether the timing of administration, dosage schedule or mode of delivery with a positive risk:benefit ratio can be identified.

\section{Systemic administration}

\section{(a) Timing of administration}

In the numerous randomised trials of corticosteroids, the timing of commencement of corticosteroid administration has varied from the first few days to many weeks after birth. The systematic reviews reported in the Cochrane database have, therefore, been subdivided into three groups: timing of commencement at less than 96 hours of age (21 trials), between seven and fourteen days (7 trials) and after three weeks of age (9 trials) [13-15]. Meta-analysis of the results of the trials included in those subgroups have demonstrated the timing of commencement of administration does influence the impact of corticosteroids treatment (table 1). Commencement of corticosteroids at all three time periods was associated with a significant reduction in chronic oxygen dependency at 36 weeks PMA and need for treatment with rescue corticosteroids (table 1). Only commencing corticosteroids between seven to fourteen days, however, was associated with a significant reduction in mortality and this was only at 28 days. The need for home oxygen therapy was only significantly reduced if the corticosteroids were commenced after three weeks of age.

\section{(b) Dosage schedule}

A variety of doses and durations of corticosteroid treatment have been investigated. A sensitivity analysis of the results of ten studies, in which 
Table 1. - Positive effects of corticosteroid therapy related to timing of commencement [13-15]

\begin{tabular}{|c|c|c|c|c|c|c|}
\hline & \multicolumn{2}{|c|}{$<96 h o u r s$} & \multicolumn{2}{|c|}{ 7-14days } & \multicolumn{2}{|c|}{ >3weeks } \\
\hline & $\mathbf{R R}$ & $95 \% \mathrm{CI}$ & $\mathbf{R R}$ & $95 \% \mathrm{CI}$ & $\mathbf{R R}$ & $95 \% \mathrm{CI}$ \\
\hline \multicolumn{7}{|l|}{$\begin{array}{l}\text { Chronic oxygen } \\
\text { dependency at }\end{array}$} \\
\hline 28 days & 0.85 & $0.79,0.92$ & 0.87 & $0.81,0.94$ & & \\
\hline 36 wks PMA & 0.69 & $0.60,0.80$ & 0.62 & $0.47,0.82$ & 0.69 & $0.49,0.98$ \\
\hline \multicolumn{7}{|l|}{ Mortality } \\
\hline 28 days & 1.05 & $0.90,1.22$ & 0.44 & $0.24,0.80$ & & \\
\hline Prior to discharge & 1.02 & $0.90,1.17$ & 0.66 & $0.40,1.09$ & 1.03 & $0.71,1.51$ \\
\hline \multicolumn{7}{|l|}{$\begin{array}{l}\text { Death or chronic } \\
\text { oxvgen dependency at }\end{array}$} \\
\hline 28 days & 0.91 & $0.86,0.96$ & 0.86 & $0.81,0.91$ & & \\
\hline 36 wks PMA & 0.86 & $0.79,0.94$ & 0.63 & $0.51,0.78$ & 0.73 & $0.58,0.93$ \\
\hline \multicolumn{7}{|l|}{ Failure to extubate } \\
\hline 28 days & 0.80 & $0.67,0.96$ & 0.71 & $0.29,1.75$ & 0.55 & $0.33,0.90$ \\
\hline Need for rescue steroids & 0.70 & $0.63,0.78$ & 0.50 & $0.35,0.71$ & 0.40 & $0.28,0.57$ \\
\hline Need for home oxygen & 0.75 & $0.53,1.07$ & 0.67 & $0.12,3.71$ & 0.66 & $0.47,0.92$ \\
\hline
\end{tabular}

dexamethasone was commenced during the first two weeks, highlighted that any benefit was not enhanced by giving doses greater than 0.5 $\mathrm{mg} / \mathrm{kg} /$ day or continuing the course for longer that 7 to 14 days [16]. Shorter courses have been assessed. Three days or less of systemic treatment, however, does not reduce CLD [17], even if followed by an 18 day course of inhaled treatment [18]. There may, however, be benefit if courses are repeated at 10 day intervals [19].

\section{Mode of administration}

\section{(a) Inhaled therapy}

In an effort to avoid the adverse effects of systemic treatment (see later) the efficacy of inhaled steroid therapy has been explored. Meta analysis of the results of eight randomised trials [20] highlighted that administration by the inhaled route during the first two weeks after birth did not reduce CLD. This treatment, however, did facilitate extubation and reduced the need for "rescue" treatment with systemic steroids.

It is possible that at least in certain trials, drug delivery via the inhaled route was poor, reducing the efficacy of the mode of administration. Even if a rigid spacer is used with a metered dose inhaler and the spacer device's non re-breathing valve is removed, less than $4 \%$ of the activated dose leaves via the endotracheal tube [21]. In one of the trials [22], however a rigid spacer device was used and, although its valve remained in situ, the researchers compensated for the low amount of drug delivered by accentuation, because on each occasion activating the metered dose inhaler sufficient times to ensure the desired dose reached the lungs. They also optimised drug delivery by giving the corticosteroids via an endotracheal tube into the pharynx once the baby was extubated and used one of the longer regimens examined to date. Nevertheless, they [22] demonstrated limited effects of inhaled beclomethasone, that is at 28 days fewer infants were receiving systemic corticosteroid treatment or mechanical ventilation.

\section{(b) Inhaled versus systemic treatment}

Comparison of inhaled versus systemically administered corticosteroids in ventilator dependent infants in two randomised trials did not demonstrate any significant differences in the mortality rate or incidence of chronic oxygen dependency at 28 days [23], but the duration of requirement for mechanical ventilation and supplementary oxygen was significantly longer in those infants who received inhaled steroids [23]. Those results are in keeping with the findings of a randomised trial which included non ventilated infants [24]; systemic steroids were demonstrated to have a more rapid and greater magnitude of effect than inhaled steroids. In addition, in another study [25] a three day course of systemic steroids was more effective than a ten day course of inhaled steroids in reducing the inspired oxygen requirement and levels of inflammatory mediators. In the OSECT trial [26] no significant differences were found with regard to oxygen dependency at 36 weeks or death between infants given inhaled or systemic therapy. Surfactant administration and the duration of therapy, however, differed between centres which may have biased the results.

\section{Adverse effects of systemic corticosteroids}

\section{(a) Acute}

Hyperglycaemia and hypertension frequently result from treatment with corticosteroids regard- 
Table 2. - Adverse effects of corticosteroids related to timing of commencement of therapy [13-15]

\begin{tabular}{|c|c|c|c|c|c|c|}
\hline & \multicolumn{6}{|c|}{ Time of dexamethasone administration } \\
\hline & \multicolumn{2}{|c|}{$<96$ hours } & \multicolumn{2}{|c|}{ 7-14 days } & \multicolumn{2}{|c|}{$>3$ weeks } \\
\hline & $\mathbf{R R}$ & $95 \% \mathrm{CI}$ & $\mathbf{R R}$ & $95 \% \mathrm{CI}$ & $\mathbf{R R}$ & $95 \% \mathrm{CI}$ \\
\hline Hyperglycaemia & 1.36 & $1.23,1.51$ & 1.51 & $1.20,1.90$ & 1.42 & $0.97,2.07$ \\
\hline Hypertension & 1.84 & $1.54,2.21$ & 2.73 & $1.25,5.95$ & 2.61 & $1.29,5.26$ \\
\hline HOCM & 4.33 & $1.40,13.4$ & 3.29 & $1.50,7.20$ & & \\
\hline Infection & 1.01 & $0.90,1.14$ & 1.35 & $1.06,1.71$ & 1.03 & $0.77,1.40$ \\
\hline GI Bleed & 1.90 & $1.35,2.66$ & 1.74 & $1.02,2.98$ & 1.13 & $0.74,1.73$ \\
\hline Intestinal Perforation & 1.98 & $1.32,2.95$ & & & 0.36 & $0.02,8.05$ \\
\hline NEC & 0.87 & $0.62,1.23$ & 0.76 & $0.38,1.49$ & 2.59 & $0.61,10.9$ \\
\hline Severe IVH & 0.95 & 0.80 .1 .12 & 0.44 & $0.17,1.15$ & & \\
\hline PVL & 1.37 & $0.91,2.05$ & & & & \\
\hline ROP & 0.86 & $0.73,1.02$ & 1.01 & $0.61,1.70$ & 1.52 & $1.09,2.12$ \\
\hline
\end{tabular}

less of the timing of commencement of administration (table 2). The median rise in systolic blood pressure has been reported to be $34 \mathrm{~mm} \mathrm{Hg}$ (range 4-49 mm Hg) [27]; similar effects are seen regardless of the postnatal age at the commencement of administration [28]. The likelihood for requiring treatment for hypertension is also increased (RR 2.7, 95\%CI 1.0-7.4) [29]. Hypertrophic obstructive cardiomyopathy (HOCM) can occur if dexamethasone is started in the first two weeks after birth (table 2). In one study [30], left ventricular hypertrophy was observed in $94 \%$ of 31 infants, but spontaneously resolved [30]. If, however, corticosteroids are given early, this is associated with a lower incidence of patent ductus arteriosus (RR 0.75 (95\%CI 0.68,0.83) [31]. Higher rates of infection have been reported in infants who receive dexamethasone (table 2); the occurrence of candida sepsis has been reported to be significantly related to duration of early dexamethasone treatment [32]. Increased rates of necrotising enterocolitis (NEC), gastrointestinal (GI) bleed and intestinal perforation have been reported, particularly if dexamethasone is administered within 96 hours of birth [29]. Dexamethasone treatment is associated with hypothalamicpituitary-adrenal axis suppression [33-35], at the level of the pituitary [34]. The effect is shortlived, with cortisol levels returning to normal by day 10 [33]. No evidence of adrenal suppression has been found following inhaled beclomethasone [36]. Neither the incidence of severe intraventricular haemorrhage (IVH) nor periventricular leucomalacia (PVL) are significantly influenced by systemic corticosteroid therapy. Although in one study [37], $75 \%$ of infants with severe Retinopathy of Prematurity (ROP) (at least stage III) had received dexamethasone, no statistically significant differences were highlighted by the meta analysis of the results of randomised trials included in the Cochrane reviews (table 2). A slower growth rate occurs in infants receiving dexamethasone [29, 38]; inhaled steroids have less effect on short-term growth than systemic therapy [39].

\section{(b) Longer term adverse effects}

Early administration of dexamethasone has been associated with an increased incidence of cerebral palsy (49\% versus $15 \%$ : odds ratio 4.62 , 95\%CI 2.38-8.98), and an increased frequency of developmental delay ( $55 \%$ versus $29 \%$; odds ratio 2.87, 95\%CI 1.53-5.38) [40]. Similar worrying trends have been demonstrated in Cochrane reviews [13-17], particularly if treatment was commenced in the first 96 hours (table 3). At school age, children who had received dexamethasone in the first 12 hours after birth experienced adverse effects on growth, intelligent quotient and motor performance [41]. This is in keeping with the finding that cerebral cortical gray matter growth has been noted to be reduced by $35 \%$ in premature infants who received dexamethastone [42]. The rate of motor dysfunction is also significantly higher if corticosteroids have been given [43]. No statistically significant effects on major neurosensory disability, blindess or deafness, however, have been highlighted by Cochrane reviews (table 3 ).

\section{Discussion}

This review highlights that, although systemic administration of corticosteroids is associated with a reduction in chronic lung disease and 28 day mortality if treatment is commenced between 7 to 14 days, this therapy has important adverse long term effects (table 3 ). In addition, although inhaled steroids have less adverse effects, they are less efficacious and not associated with reductions in either CLD or mortality.

The results of a recent survey [44] demonstrate that, at least UK neonatologists, have come to different conclusions from the literature regarding the balance between the risks and benefits of corticosteroid therapy. Thirty-three percent never prescribed corticosteroids and approximately four percent gave inhaled steroids only. Although, there was consistency in that none prescribed corticosteroids in the first week after birth, 33\% com- 
Table 3. - Longer term adverse effects of corticosteroid treatment related to timing of commencement of administration [13-15]

\begin{tabular}{|c|c|c|c|c|c|c|}
\hline & \multicolumn{6}{|c|}{ Time of dexamethasone administration } \\
\hline & \multicolumn{2}{|c|}{$<96$ hours } & \multicolumn{2}{|c|}{ 7-14 days } & \multicolumn{2}{|c|}{ >3 weeks } \\
\hline & $\mathbf{R R}$ & $95 \% \mathrm{CI}$ & $\mathbf{R R}$ & $95 \% \mathrm{CI}$ & $\mathbf{R R}$ & $95 \% \mathrm{CI}$ \\
\hline Developmental Delay & 1.68 & $1.08,2.61$ & & & & \\
\hline Cerebral Palsy & 1.69 & $1.20,2.38$ & 0.83 & $0.39,1.74$ & 1.20 & $0.77,1.85$ \\
\hline Abnormal Neurology & 1.81 & $1.33,2.47$ & & & 1.90 & $1.08,3.33$ \\
\hline Major neurosensory & & & 0.89 & $0.38,2.10$ & 1.13 & $0.73,1.75$ \\
\hline \multicolumn{7}{|l|}{ Disability } \\
\hline Blindness & & & 0.38 & $0.08,1.78$ & 1.44 & $0.43,4.78$ \\
\hline Deafness & & & 0.50 & $0.05,4,94$ & 1.24 & $0.34,4.53$ \\
\hline
\end{tabular}

menced steroids outside the neonatal period and only $21 \%$ in the second week after birth, despite that timing being associated with a significant reduction in 28 day mortality. Almost half (47.7\%) prescribed $0.5 \mathrm{mg} / \mathrm{kg} / \mathrm{day}$, but despite the sensitivity analysis of Bhuta and Ohlsson [16] $19 \%$ gave a larger daily dose. Similarly, although the sensitivity analysis [16] highlighted that no greater beneficial effects were achieved if the course was extended beyond 14 days and no positive benefit if a single three day course was given, $15 \%$ prescribed three days of therapy; $29 \%$ seven days, $22 \%$ ten days, $18 \% 14$ days and $4 \%$ six weeks duration of therapy. Recent guidelines [45] have suggested that, until clear benefits of corticosteroids have been identified and the long term neuro-developmental outcomes clarified, dexamethasone use should be limited to exceptional clinical circumstances or only given within the context of randomised controlled trials. The reported survey [44] highlights that at least in the UK, such recommendations are not consistently followed and this is likely to reflect the lack of a safe and effective strategy to prevent CLD. It is, therefore, vital that an accurate method of identifying infants at very high risk of developing CLD is found, a corticosteroid regime with a positive risk:benefit regime highlighted or preferably a safer and more effective therapy discovered.

\section{References}

1. Johnson AH, Peacock, JL, Greenough A et al. High-frequency oscillatory ventilation for the prevention of chronic lung disease of prematurity. $N$ Engl J Med 2002; 347: 633-42.

2. Greenough A, Alexander J, Burgess S et al. Home oxygen status and rehospitalisation and primary care requirements of infants with chronic lung disease. Arch Dis Child 2002; 86: 40-3.

3. Greenough A, Milner AD, Dimitriou G. Synchronized mechanical ventilation for respiratory support in newborn infants. Cochrane Database Syst Rev 2001: CD000456

4. Greenough A. Respiratory support techniques for prematurely born infants: new advances and perspectives. Acta Paediatr Taiwan 2001; 42: 201-6.
5 Van Marter LJ, Allred EN, Leviton A, Pagano M, Parad $\mathrm{R}$, Moore M. Antenatal glucocorticoid treatment does not reduce chronic lung disease among surviving preterm infants. J Pediatr 2001; 138: 198-204.

6. Jobe AH. Pulmonary surfactant therapy. $N$ Engl J Med 1993; 328(12): 861-8.

7 Kavvadia V, Greenough A, Dimitriou G, Hooper R. Randomised trial of fluid restriction in ventilated very low birthweight infants. Arch Dis Child Fetal Neonatal Ed 2000; 83: F91-6.

8. Speer CInflammation and bronchopulmonary dysplasia. Semin Neonatol 2003; 8: 29-38.

9. Jobe AH, Ikegami M. Mechanisms initiating lung injury in the preterm. Early Hum Dev 1998; 53: 81-94.

10. Vyas J, Kotecha S. Effects of antenatal and postnatal corticosteroids on the preterm lung. Arch Dis Child Fetal Neonatal Ed 1997; 77: F147-50.

11. Groneck P, Reuss D, Gotze-Speer B, Speer C. Effects of dexamethasone on chemotactic activity and inflammatory mediators in tracheobronchial aspirates of preterm infants at risk for chronic lung disease. $\mathrm{J} \mathrm{Pedi-}$ atr 1993; 122: 938-44

12. Wang JY, Yeh TF, Lin YC, Miyamura K, Holmskov U, Reid KB. Measurement of pulmonary status and surfactant protein levels during dexamethasone treatment of neonatal respiratory distress syndrome. Thorax 1996; 51: 907-13.

13. Halliday HL, Ehrenkranz RA, Doyle LW. Early postnatal ( $<96$ hours) corticosteroids for preventing chronic lung disease in preterm infants. Cochrane Database Syst Rev 2003: CD001146.

14. Halliday HL, Ehrenkranz RA, Doyle LW. Moderately early (7-14 days) postnatal corticosteroids for preventing chronic lung disease in preterm infants. Cochrane Database Syst Rev 2003: CD001144.

15. Halliday HL, Ehrenkranz RA, Doyle LW. Delayed (>3 weeks) postnatal corticosteroids for chronic lung disease in preterm infants. Cochrane Database Syst Rev 2003: CD001145

16 Bhuta T, Ohlsson A. Systematic review and metaanalysis of early postnatal dexamethasone for prevention of chronic lung disease. Arch Dis Child Fetal Neonatal Ed 1998; 79: F26-33.

17. Shinwell ES, Karplus M, Zmora E et al. Failure of early postnatal dexamethasone to prevent chronic lung disease in infants with respiratory distress syndrome. Arch Dis Child 1996; 74: F33-37

18. Kovacs L, Davis GM, Faucher D, Papageorgiou A. Efficacy of sequential early systemic and inhaled corticosteroid therapy in the prevention of chronic lung disease of prematurity. Acta Paediatr 1998; 87: 792-8. 
19 Brozanski BS, Jones JG, Gilmour CH. Effect of pulse dexamethasone therapy on the incidence and severity of chronic lung disease in the very low birth weight infant. J Pediatr 1995; 126: 769-76.

20 Shah V, Ohlsson A, Halliday HL, Dunn MS. Early administration of inhaled corticosteroids for preventing chronic lung disease in ventilated very low birth weight preterm neonates. Cochrane Database Syst Rev 2000: CD001969.

21 Fok TF, Lam K, Chan CK et al. Aerosol delivery to non-ventilated infants by metered dose inhaler: should a valved spaced be used? Pediatr Pulmonol 1997; 24: 204-12

22 Cole CH, Colton T, Shal BL et al. Early inhaled glucocorticoid therapy to prevent bronchopulmonary dysplasia. N Engl J Med 1999; 340: 1005-10.

23 Halliday HL. Clinical trials of postnatal corticosteroids: inhaled and systemic. Biol Neonate 1999; 76 Suppl 1: 29-40.

24 Dimitriou G, Greenough A, Giffin FJ, Kavvadia V. Inhaled versus systemic steroids in chronic oxygen dependency of preterm infants. Eur J Pediatr 1997; 156: 51-5.

25 Groneck P, Goetze-Speer B, Speer C. Effects of inhaled beclomethasone compared to systemic dexamethasone on lung inflammation in preterm infants at risk of chronic lung disease. Pediatr Pulmonol 1999; 27: 383-7.

26 Halliday HL, Patterson CC, Halahakoon CW. A multicenter, randomized open study of early corticosteroid treatment (OSECT) in preterm infants with respiratory illness: comparison of early and late treatment and of dexamethasone and inhaled budesonide. Pediatrics 2001; 107: 232-40.

27 Smets K, Vanhaesebrouck. Dexamethasone associated systemic hypertension in low birth weight babies with chronic lung disease. Eur J Pediatr 1996; 155: 573-5.

28 Emery EF, Greenough A. Effect of dexamethasone on blood pressure: relationship to postnatal age. Eur J Pediatr 1992;151:364-6

29 Stark AR, Carlo WA, Tyson JE et al. Adverse effects of early dexamethasone in extremely-low-birth-weight infants. National Institute of Child Health and Human Development Neonatal Research Network. $N$ Engl J Med 2001; 344: 95-101.

30 Skelton R,Gill AB, Parsons JM. Cardiac effects of short course dexamethasone in preterm infants. Arch Dis Child Fetal Neonatal Ed 1998; 78: F133-7.

31 Halliday HL, Ehrenkranz RA. Early postnatal $(<96$ hours) corticosteroids for preventing chronic lung disease in preterm infants. Cochrane Database Syst Rev 2000: CD001146.
32 Pera A, Byun A, Gribar S, Schwartz R, Kumar D, Parimi Dexamethasone therapy and Candida sepsis in neonates less than 1250 grams. J Perinatol 2002; 22: 204-8.

33. Wilson DM, Baldwin RB, Ariagno RL. A randomized, placebo-controlled trial of effects of dexamethasone on hypothalamic-pituitary-adrenal axis in preterm infants. J Pediatr 1988; 113: 764-8.

34. Rizvi ZB Aniol HS, Myers TF, Zeller WP, Fisher SG, Anderson CL. Effects of dexamethasone on the hypothalamic-pituitary-adrenal axis in preterm infants. $J P e$ diatr 1992; 120: 961-5.

35. Alkalay AL, Pomerance JJ, Puri AR et al. Hypothalamic-pituitary-adrenal axis function in very low birth weight infants treated with dexamethasone. Pediatrics 1990. 86: 204-10.

36. Cole $\mathrm{CH}$, Shah $\mathrm{B}$, Abbasi $\mathrm{S}$ et al. Adrenal function in premature infants during inhaled beclomethasone therapy. J Pediatr 1999; 135: 65-70.

37 Ramanathan R Siassi B, deLemos RA. Severe retinopathy of prematurity in extremely low birth weight infants after short-term dexamethasone therapy. J Perinatol 1995; 15: 178-82; quiz 183-4.

38 Shrivastava A, Lyon A, McIntosh N. The effect of dexamethasone on growth, mineral balance and bone mineralisation in preterm infants with chronic lung disease. Eur J Pediatr 2000; 159: 380-4.

39 Nicholl RM, Greenough A, King M, Cheeseman P, Gamsu HR. Growth effects of systemic versus inhaled steroids in chronic lung disease. Arch Dis Child Fetal Neonatal Ed 2002; 87: F59-61.

40 Shinwell ES, Karplus M, Reich D et al. Early postnatal dexamethasone treatment and increased incidence of cerebral palsy. Arch Dis Child Fetal Neonatal Ed 2000; 83: F177-81.

41 Yeh TF, Lin YJ, Lin HC et al. Outcomes at school age after postnatal dexamethasone for lung disease of prematurity. New Engl J Med 2004; 350: 1304-13

42 Murphy BP, Inder TE, Huppi PS et al. Impaired cerebral cortical gray matter growth after treatment with dexamethasone for neonatal chronic lung disease. Pediatrics 2001; 107: 217-21.

43 Doyle L, Davis Postnatal corticosteroids in preterm infants: systematic review of effects on mortality and motor function. J Paediatr Child Health 2000; 36: 101-7.

44 Williams O, Greenough A. Post-natal corticosteroid use. Eur J Pediatr 2003; 162: 613-5.

45 American Academy of Pediatrics on Fetus and Newborn and Canadian Paediatric Society. Postnatal corticosteroids to treat or prevent chronic lung disease in preterm infants. Pediatrics 2002; 109: 330-338.

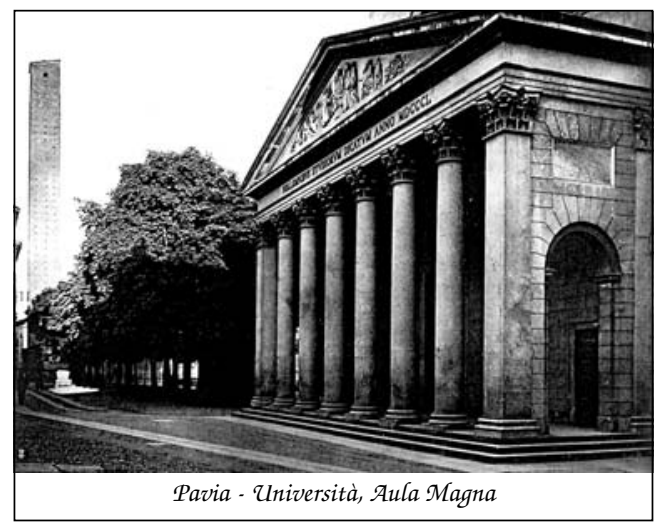

